\title{
The combination effect of homoharringtonine and ibrutinib on FLT3-ITD mutant acute myeloid leukemia
}

This article has been corrected. Correction in: Oncotarget. 2019; 10:6641-6642.

Xia Li ${ }^{1,2, *}$, Xiufeng Yin ${ }^{1,2, *}$, Huafeng Wang ${ }^{1,2}$, Jiansong Huang ${ }^{1,2}$, Mengxia Yu ${ }^{1,2}$, Zhixin Ma ${ }^{1,2}$, Chenying Li ${ }^{1,2}$, Yile Zhou ${ }^{1,2}$, Xiao Yan ${ }^{1,2}$, ShuJuan Huang ${ }^{1,2}$, Jie Jin ${ }^{1,2,3}$

${ }^{1}$ Department of Hematology, The First Affiliated Hospital of Zhejiang University, Hangzhou, People's Republic of China

${ }^{2}$ Institute of Hematology, Zhejiang University School of Medicine, Hangzhou, People's Republic of China

${ }^{3}$ Key Lab of Hematopoietic Malignancy, Zhejiang University, Hangzhou, Zhejiang, People's Republic of China

*These authors contributed equally to this work and share first authorship

Correspondence to: Jie Jin, email: zjuhematology@163.com

Keywords: acute myeloid leukemia, FLT3-ITD, homoharringtonine, ibrutinib

Received: February 25, $2016 \quad$ Accepted: December 25, $2016 \quad$ Published: January 03,2017

\section{ABSTRACT}

Acute myeloid leukemia (AML) is a highly heterogeneous disease and internal tandem duplication mutation in FMS-like tyrosine-kinase-3 (FLT3-ITD) has a negative impact on outcome. Finding effective treatment regimens is desperately needed. In this study, we explored the inhibitory effect and mechanism of homoharringtonine (HHT) in combination with ibrutinib on FLT3-ITD mutant AML cells. Consequently, we observed a synergistic inhibitory effect when ibrutinib was combined with HHT to inhibit cell proliferation, induce apoptosis and arrest cell cycle at G0/G1 phase in MV4-11 and MOLM-13 leukemia cells. Our results indicate that the mechanisms of the combination effect are mainly via regulating the STAT5/Pim-2/C-Myc pathway, AKT pathway and Bcl-2 family, activating p21WAF1/CIP1 and inhibiting CCND/CDK complex protein. Interestingly, synergistic cytotoxicity of ibrutinib and HHT was dependent on both FLT3 and BTK. Here we provide a novel effective therapeutic approach for the treatment of AML patients with FLT3-ITD mutation.

\section{INTRODUCTION}

Acute myeloid leukemia (AML) has achieved a high prevalence of complete remission (CR) with the gold standard for induction chemotherapy using daunorubicin and cytarabine [1,2]. However, approximately $20 \% \sim 30 \%$ AML patients harbor an internal tandem duplication mutation of the FMS-like tyrosine kinase receptor (FLT3ITD mutation) that was considered to be unfavorable. The $\mathrm{CR}$ rate was lower and the overall and disease-free survival was shorter than non-FLT3-ITD AML patients [3-6]. Until now, effective treatment regimens for FLT3-ITD mutant AML were still lacking and represent an urgent need.

Homoharringtonine (HHT) is a natural alkaloid derived from trees of Cephalotaxus and has been studied and used in China for the treatment of hematological diseases for the past 30 years. The mechanisms are not very clear but it works by inhibiting protein synthesis $[7,8]$ by preventing the initial elongation step of protein synthesis via an interaction with the ribosomal A-site and reducing p-eIF4E levels [9]. This leads to a rapid loss of proteins with short half-lives such as c-Myc, Mcl-1 and CyclinD1. In in vitro and in vivo studies, HHT has been reported to act against AML [10-12], MDS [13-15] and CML [16-19] cells. In an open-label, randomized, controlled phase III study performed by our group, the homoharringtoninebased induction regimen HAA (homoharringtonine, cytarabine and aclarubicin) showed $73 \%$ of patients (150/206) with AML (non-acute promyelocytic leukemia (APL)) achieved CR, which was significantly higher than that in the DA (daunorubicin and cytarabine) group $(61 \%, 125 / 205)$ [10]. Also in their study, 40 FLT3-ITD mutant patients were included and the HAA regimen showed good curative effect of treatment. Recently, as reported by Xu et al. [20], sorafenib in combination with low-dose homoharringtonine as a salvage therapy was successfully administrated and obtained CR in primary refractory FLT3-ITD mutant AML. In conclusion, regimen including HHT has been used as alternative valid front line chemotherapy for AML in China.

Recently, some groups have shown that the inhibitor of Bruton's tyrosine kinase (BTK) ibrutinib blocks AML 
cell proliferation, adhesion to bone marrow stromal cells as well as migration [21-23]. Recently, one study indicated that ibrutinib combined with ethacridine had a synergistic cytotoxicity to AML cells [24]. Interestingly, Pillinger et al. and $\mathrm{Wu}$ et al. found ibrutinib was particularly effective in inhibiting FLT3-ITD mutant AML cell survival [25, 26]. They have confirmed that ibrutinib blocks the FLT3 mutation signaling pathway and inhibits the expression of STAT5, ERK, AKT, and C-Myc to suppress FLT3-ITD mutant AML cell growth. All these observations helped to promote the application of ibrutinib to FLT3-ITD mutant AML.

In this study, our group combined HHT with ibrutinib in AML cell lines and primary AML cells to identify the synergistic effect. We mainly studied the mechanisms in FLT3-ITD mutant AML cells. Finally, we provided a novel combination strategy in FLT3-ITD mutant AML patients.

\section{RESULTS}

\section{HHT and ibrutinib synergistically inhibited growth of AML cell lines and primary AML cells}

The growth inhibition of AML cells by HHT or ibrutinib was examined. AML cells were plated into 96-well plates and treated with increasing concentrations of HHT $(2,4,8,16$ and $32 \mathrm{nM})$ or ibrutinib $(0.625,1.25,2.5,5$ and $10 \mu \mathrm{M})$ and equal volumes of DMSO for $24 \mathrm{~h}$. Both HHT and ibrutinib showed higher sensitivity in MV4-11 and MOLM-13 cells (Figure 1A). As reported before, ibrutinib was more effective in inhibiting FLT3-ITD mutant AML cells [25, 27], similar to the findings in our study. The IC50s at $24 \mathrm{~h}$ for HHT and ibrutinib are presented in Supplementary Table 1. Following treatment with increasing doses of HHT or ibrutinib for $24 \mathrm{~h}$ and $48 \mathrm{~h}$, MV4-11 and MOLM-13 cell viability was found to be significantly inhibited in a dose dependent manner. When HHT was combined with ibrutinib, they synergistically inhibited growth of AML cell lines (Figure 1) and similar results were achieved in primary AML cells (Figure 2). The characteristics of the patient samples are presented in Supplementary Table 2. The dose-effect curves were determined by Calcusyn analyses. CIs at the ED50, ED75 and ED90 are presented in Figures 1 and 2. CI $<1.0$ means a synergistic effect. So we confirmed that HHT combined with ibrutinib had a strong synergistic effect in AML cell lines and primary AML cells in vitro.

\section{HHT and ibrutinib synergistically induced apoptosis of FLT3-ITD $(+)$ AML cells}

In this study, we investigated if these two drugs could synergistically induce apoptosis of FLT3-ITD mutant AML cells. Cells were exposed to $8 \mathrm{nM} \mathrm{HHT}$ and/or $2.5 \mu \mathrm{M}$ ibrutinib for $24 \mathrm{~h}$ and $48 \mathrm{~h}$. Compared with single agents, combination of HHT and ibrutinib resulted in a significant increase in apoptosis of MV4-11 and MOLM-13 cells (Figure 3A and 3B). Next, we analyzed the key signaling molecules in the apoptosis pathway by western blot analysis. As presented in Figure 3C, we observed that the combined treatment obviously increased the expression of cleaved PARP, caspase 8, caspase 7 and caspase 3 at $24 \mathrm{~h}$. The expression of apoptotic proteins Bad and Bax had no obvious change. The expression of main anti-apoptotic proteins including Bcl-2, Bcl-XL and MCL-1 were more significantly decreased caused by HHT combined with ibrutinib after $6 \mathrm{~h}$ exposure (Figure 4A and 4B).

\section{HHT combined with ibrutinib enhanced cell cycle arrest}

Cell cycle arrest mainly contributed to the synergistic effects of HHT and iburutinib in FLT3-ITD mutant AML cells. Treated MV4-11 and MOLM-13 cells with $2 \mathrm{nM}$ HHT or $0.625 \mu \mathrm{M}$ ibrutinib did not cause cell cycle arrest, but the group $2+0.625$ caused G0/G1 arrest (Figure 5A). When cells were treated with $4 \mathrm{nM}$ HHT and/or $1.25 \mu \mathrm{M}$ ibrutinib, we found both single agents and combination apparently caused G0/G1 arrest $(p<0.01)$ (Figure 5B). We then increased the concentration of the two agents to $8 \mathrm{nM}$ and $2.5 \mu \mathrm{M}$. Cell cycle distribution at G0/G1 phase increased, but the group of $8+2.5$ was almost the same as the $4+1.25$ group (Figure $5 \mathrm{C}$ ). This leads us to believe that when HHT is combined with ibrutinib at low concentrations the synergistic effects were via cell cycle arrest and at high concentrations the combination also caused apoptosis as showed in Figure 3. To further prove the induction of cell cycle arrest, we analyzed the expression level of G1 proteins cyclin D2/D3 (CCND2/3) and $\mathrm{G} 1$ phase enhancers cyclin dependent kinase 4, 6, 2 (CDK-4, CDK-6, CDK-2) and found obvious deceases in both low concentration and high concentration groups (Figure 5D). We found that HHT mainly down-regulated CCND3 and ibrutinib mainly down-regulated CCND2 and both CCND2 and CCND3 were obviously downregulated in combination group. We also analyzed the cyclin dependent kinase inhibitor (CDKI) P21WAF1/ CIP1. Interestingly, HHT caused a significant increase of P21WAF1/CIP1 which was not reported before. As expected, the combination of HHT and ibrutinib induced a more pronounced up-regulation of P21WAF1/CIP1 expression.

\section{The synergistic effect increased p53 through DNA damage response}

P53 is the upstream of P21WAF1/CIP1. In our study, we found that HHT obviously increased P53 and the combination of HHT and ibrutinib resulted in a more pronounced increase of P53 on the protein level. In order to investigate whether the up-regulation of P53 was dependent on DNA damage, we examined the level of $\gamma \mathrm{H} 2 \mathrm{AX}$. As shown in Figure 6, we found the combination 
group increased $\gamma \mathrm{H} 2 \mathrm{AX}$ more significantly than single agents. These data indicated that the up-regulation of P53/P21 was dependent on DNA-damage response.

\section{Modulation of oncogenic signaling pathways by HHT and ibrutinib}

FLT3-ITD mutation leads to aberrant activation of downstream kinases including MAPK, AKT and STAT5 $[25,26]$. In our study, we found the expression of phosphorylated STAT5 (p-STAT5) was notably reduced when treated with ibrutinib and the combination of HHT and ibrutinib for $6 \mathrm{~h}$ in MV4-11 and MOLM-13 cell lines (Supplementary Figure 1, Figure 7A and 7B). However, no difference was observed in phosphorylated ERK (p-ERK). When the concentration was increased to $8 \mathrm{nM} \mathrm{HHT}$ and/or $2.5 \mu \mathrm{M}$ ibrutinib, phosphorylated AKT (p-AKT) was decreased as well. Similar results in a primary AML patient were shown in Figure 7B. Next, we observed Pim kinases were regulated by STAT5, down-stream of FLT3-ITD, and found Pim-2 was obviously decreased while Pim-1 had no change. Previously, researchers have reported both HHT and ibrutinib can inhibit transcription factor C-Myc [11, 27]. This led us to measure the expression of C-Myc and found an obvious inhibition when treated with HHT and ibrutinib (Figure 7C).

The inhibitory effect of HHT combined with ibrutinib was through the down-regulation of both FLT3 and BTK pathways. To identify the effect of ibrutinib and/ or HHT on FLT3 and BTK activity, we used western blot to analyze the protein levels of FLT3, p-FLT3, BTK and

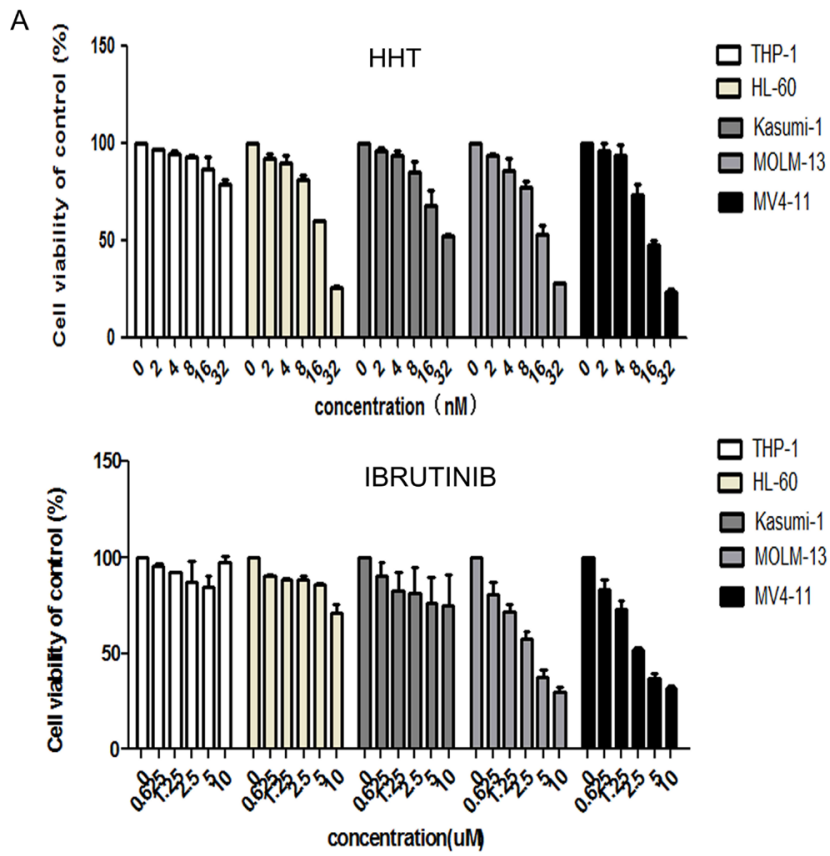

C
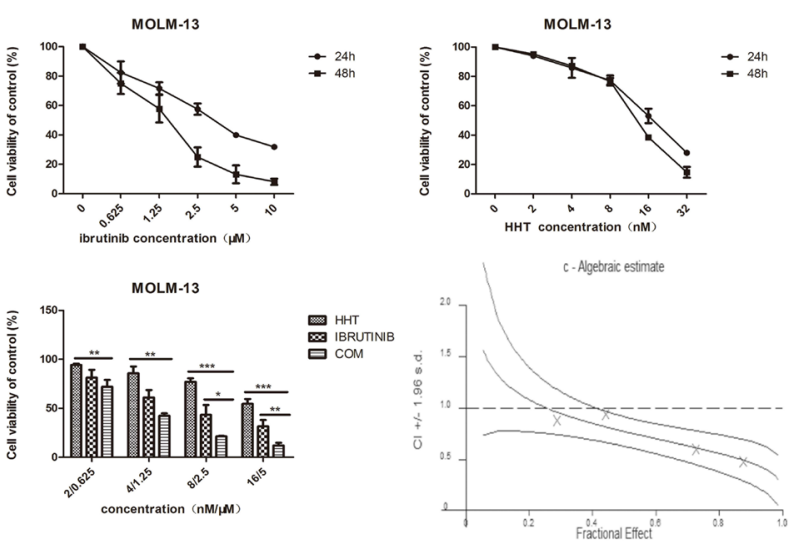

D
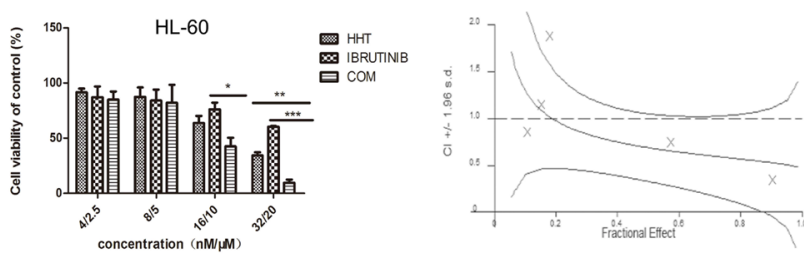

E
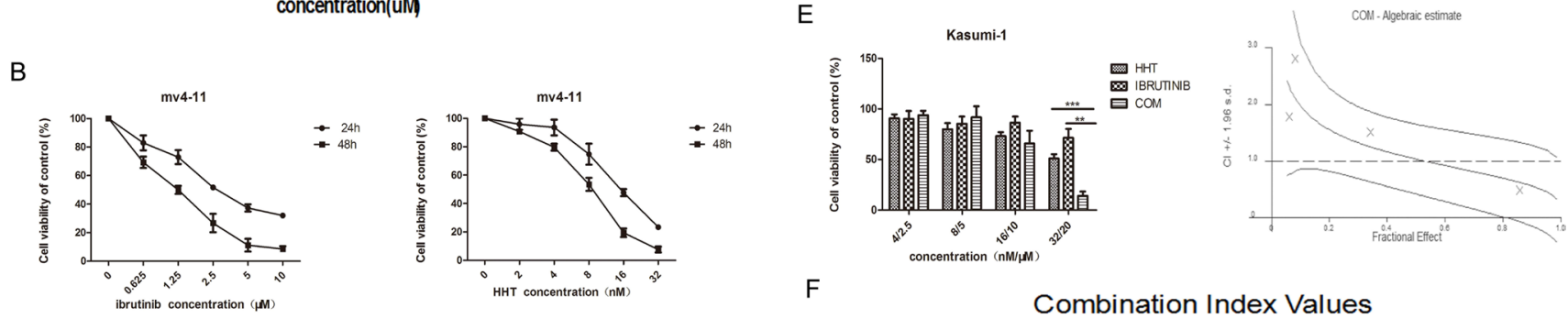

$\mathrm{F}$
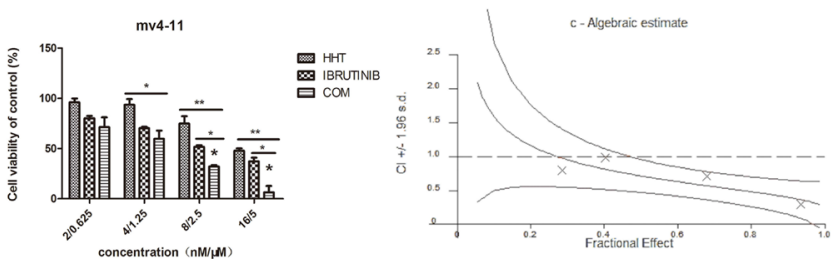

\begin{tabular}{lcccc} 
& \multicolumn{3}{c}{ Combination Index Values } \\
\cline { 2 - 5 } & MV4-11 & MOLM-13 & HL-60 & Kasumi-1 \\
\hline ED-50 & 0.7138 & 0.7710 & 0.6899 & 1.0366 \\
ED-75 & 0.5178 & 0.5964 & 0.5858 & 0.7590 \\
ED-90 & 0.3989 & 0.4655 & 0.5302 & 0.5598 \\
\hline
\end{tabular}

Figure 1: HHT and ibrutinib inhibit the growth of AML cell lines. The cell viability induced by HHT and ibrutinib in AML cell lines at $24 \mathrm{~h} \mathrm{(A).} \mathrm{The} \mathrm{rate} \mathrm{of} \mathrm{cell} \mathrm{viability} \mathrm{induced} \mathrm{by} \mathrm{HHT,} \mathrm{ibrutinib} \mathrm{and} \mathrm{HHT+ibrutinib} \mathrm{in} \mathrm{MV4-11cells} \mathrm{(B),} \mathrm{MOLM-13} \mathrm{cells} \mathrm{(C),} \mathrm{HL-60}$ cells (D) and Kasumi-1 cells (E) was measured by a MTT assay. The CI at the ED50, ED75 and ED90 were presented (F). The data are presented as mean inhibition rates $\pm \mathrm{SD}$ from at least three independent experiments. 
A

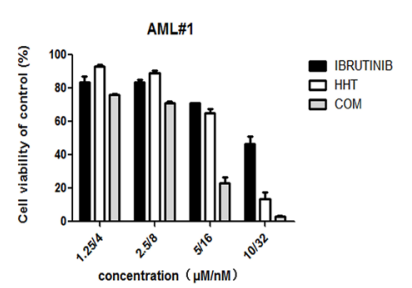

B

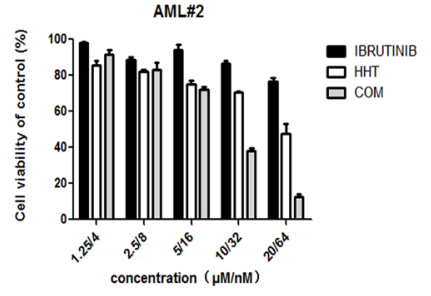

C
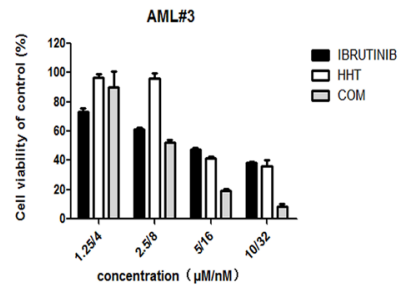
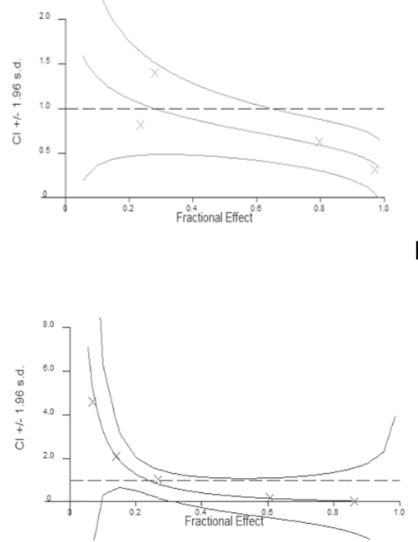

com- Algebraic estimate
D
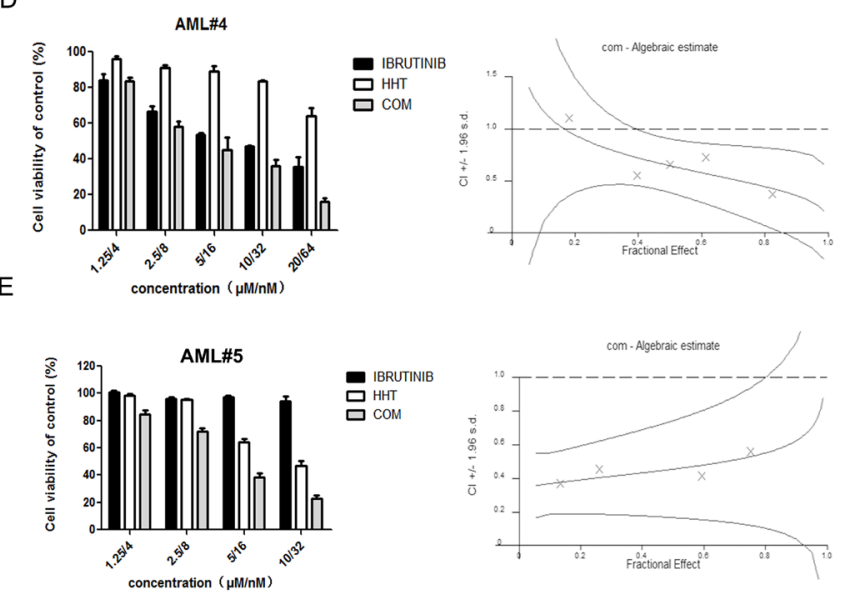

$\mathrm{F}$

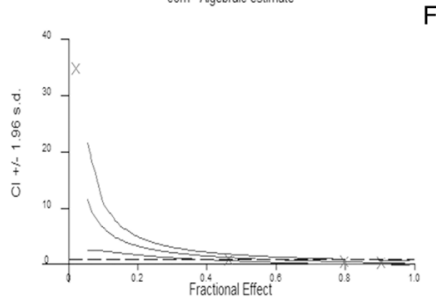

\begin{tabular}{cccccc}
\multicolumn{5}{c}{ Combination Index Values } \\
\cline { 2 - 6 } & AML\#1 & AML\#2 & AML\#3 & AML\#4 & AML\#5 \\
\hline ED-50 & 0.802 & 0.262 & 1.126 & 0.646 & 0.455 \\
ED-75 & 0.627 & 0.079 & 0.560 & 0.481 & 0.529 \\
ED-90 & 0.495 & 0.025 & 0.323 & 0.358 & 0.625 \\
\hline \multicolumn{5}{c}{ AML\#1,2,3:FLT3-ITD(+) } & AML\#4,5 :FLT3-ITD wt
\end{tabular}

Figure 2: HHT and ibrutinib inhibit the growth of primary AML cells. FLT3-ITD + primary AML cells (A-D) and FLT3-ITD wt primary AML cells $(\mathbf{E}-\mathbf{G})$ were treated with HHT, ibrutinib and HHT+ibrutinib for $24 \mathrm{~h}$. The rate of cell viability was measured by an MTT assay. The CI at the ED50, ED75 and ED90 were presented $(\mathbf{H})$.

A

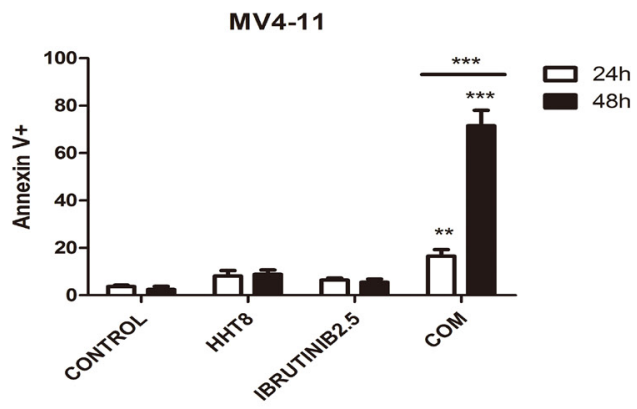

B

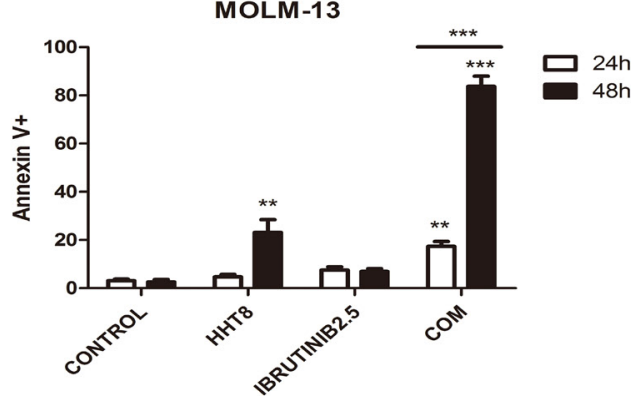

C
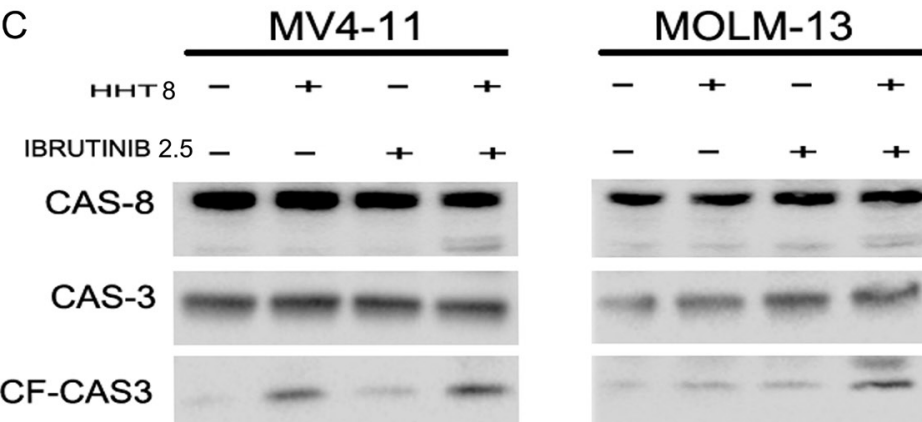

CAS-7
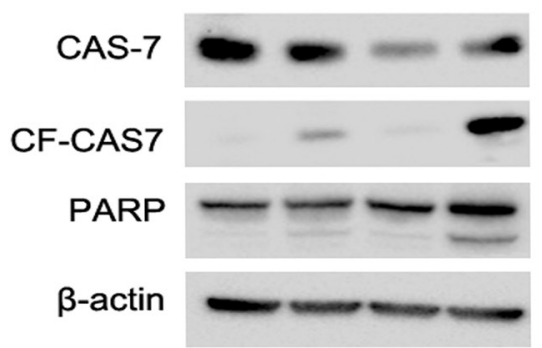
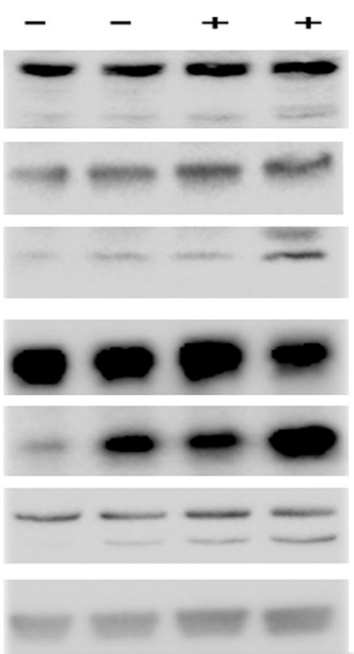

Figure 3: Apoptosis induced by HHT, ibrutinib and HHT + ibrutinib in FLT3-ITD mutant cells. (A) MV4-11 and MOLM-13 cells (B) were treated with $8 \mathrm{nM} \mathrm{HHT}$ and/or $2.5 \mu \mathrm{M}$ ibrutinib for $24 \mathrm{~h}$ and $48 \mathrm{~h}$. Cells were co-stained with Annexin V and PI and apoptosis was measured by flow cytometry. Expression of PARP, caspase- $3,-7$ and -8 were analyzed by Western blotting analyses in MV4-11 and MOLM-13 cells treated with HHT and/or ibrutinib at the indicated concentrations for $24 \mathrm{~h}(\mathbf{C})$. 
p-BTK (Y223) in MV4-11, MOLM-13 and FLT3-ITD (+) patients' cells. As a result, we found HHT decreased both total FLT3 and p-FLT3, while ibrutinib decreased p-FLT3 significantly and increased total FLT3 simultaneously. For the combination of HHT and ibrutinib, both total FLT3 and p-FLT3 were obviously decreased. Meanwhile, the combination group caused a more significant decrease in the expression of p-BTK after $6 \mathrm{~h}$ exposure (Figure 8).

\section{Ibrutinib's synergy with HHT is dependent of FLT3}

To test the synergistic effects between ibrutinib and HHT whether due to interfere to FLT3 or STAT5, we knocked down the expression of the FLT3 or STAT5gene in MV4-11 cells using siRNA technology. The reduction of FLT3 or STAT5 expression was confirmed by qPCR and western blotting (Figure 9A). Knockdown cells then were treated with increasing concentrations of ibrutinib and HHT for $24 \mathrm{~h}$. CIs at the ED50, ED75 and ED90 are presented at Figure 9B. We found that there was almost no difference between STAT5-knockdown cells and scrambled siRNA control cells. The CIs of FLT3 knockdown cells were increased compared to the scrambled siRNA control cells. When cells were treated with $0.625 \mu \mathrm{M}$ ibrutinib and $2 \mathrm{nM}$ HHT for $48 \mathrm{~h}$, compared to control siRNA treatment, the cell viability was increased in FLT3 or STAT5-knockdown cells $(P<0.05)$ (Figure 9C). These observations suggest that synergy of ibrutinib with HHT is dependent of FLT3 but not STAT5.

\section{DISCUSSION}

The treatment for FLT3-ITD mutant AML patients remains a seriously unmet medical need. Besides standard chemotherapy, there are several inhibitors such as sorafenib [31, 32], midostaurin [33], lestaurtinib [34] and quizartinib $[35,36]$ that have been used clinically to date.
However, drug resistance frequently develops within the first 12 months of treatment. Our previous studies found that chemotherapy regimen including HHT had a powerful effect in FLT3-ITD mutant patients [10]. According to the results of particularly effective effect in inhibiting FLT3-ITD mutant AML cells survival of ibrutinib, we assumed a synergistic effect between HHT and ibrutinib. Here, we mainly evaluated the effects of single agents and the combination of two agents in FLT3-ITD mutant cell lines and primary cells from FLT3-ITD mutant patients. The probable mechanisms of synergistic effect were also explored.

In this study, we showed that HHT or ibrutinib alone induced an inhibition of cell growth in MV4-11 and MOLM-13 cells in a dose-dependent manner. Both HHT and ibrutinib showed higher sensitivity in FLT3ITD + cells than FLT3-ITD wt cells. When combining HHT with ibrutinib at the molar rate 1:312.5 (HHT nM: ibrutinib $\mathrm{nM}$ ), a synergistic effect was significantly seen in ED50, 75, 90 identified by calculation of CI. Besides AML cell lines, primary AML blasts similarly showed a synergistic effect but we found no significant difference between FLT3-ITD+ and FLT3-ITD wt cells. In order to find effective treatment regimens for FLT3-ITD+ patients, FLT3-ITD+ AML cells were used in most experiments for exploring the mechanisms of the synergistic effect.

From our study, we found that the combination therapy enhanced apoptosis and cell cycle arrest, which might be the key factor of the synergistic effect mechanisms. To further elucidate the mechanisms involved in the synergistic effect, western blotting was used to identify the pathway modulated by HHT and ibrutinib.

As previously reported, HHT decreased protein expression levels of PI3K110 and P-AKT in THP-1 and Kasumi cells [11], and possibly acted as a broad-spectrum PTK inhibitor and inhibited JAK2-STAT5 signaling pathway in AML cells [37]. According to our results, HHT was found to slightly down regulate the expression of
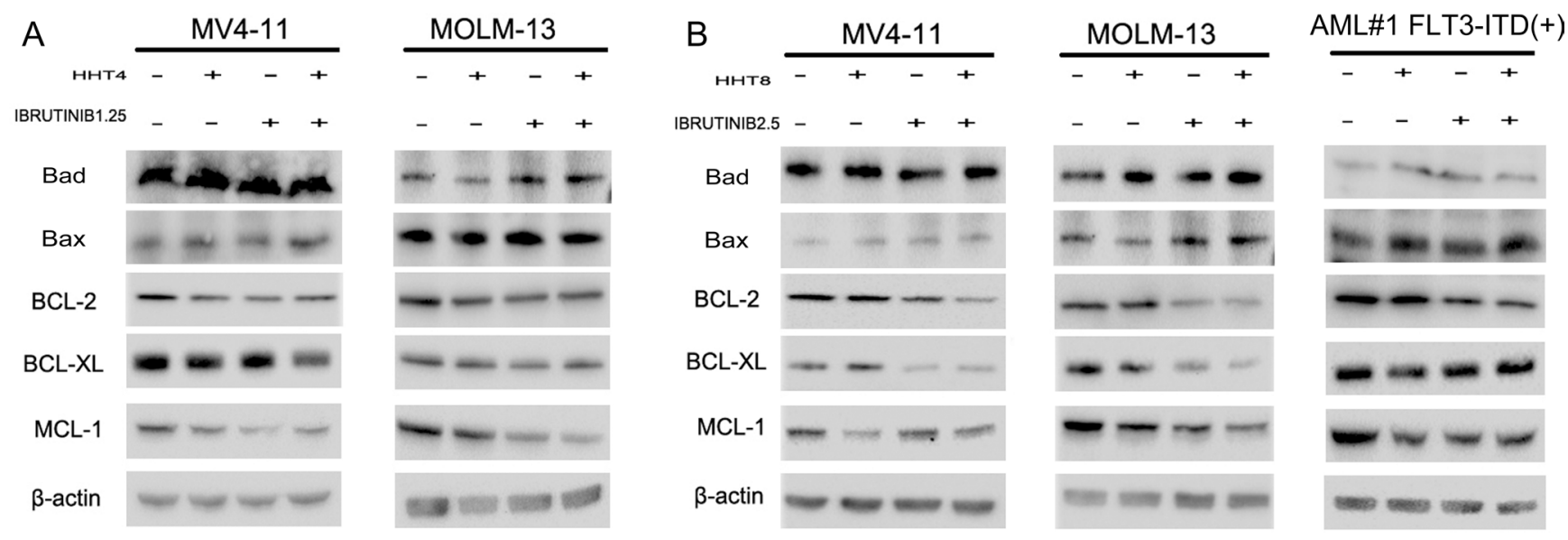

Figure 4: HHT combination ibrutinib inhibits BCL-2 family signaling. (A and C) MV4-11 and MOLM-13 cells were treated with $4 \mathrm{nM} \mathrm{HHT}$ and/or 1.25 ibrutinib for $6 \mathrm{~h}$. (B and D) MV4-11, MOLM-13 and primary AML cells were treated with $8 \mathrm{nM} \mathrm{HHT}$ and/or $2.5 \mu \mathrm{M}$ ibrutinib for $6 \mathrm{~h}$. Western blot analysis was conducted for $\mathrm{p}-\mathrm{Bad}, \mathrm{Bad}, \mathrm{Bax}, \mathrm{Bcl}-2, \mathrm{Bcl}-\mathrm{xL}$ and Mcl-1protein levels. 
A
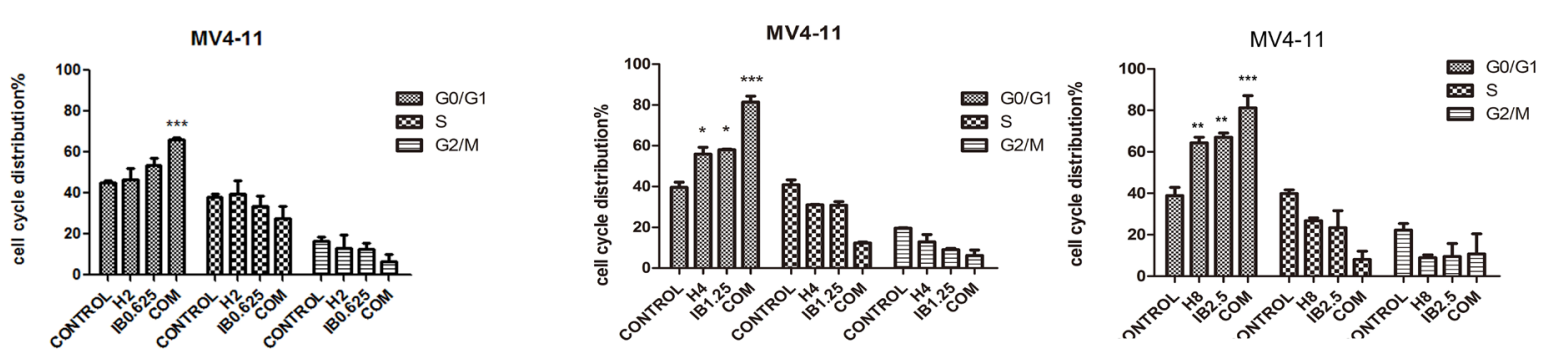

B
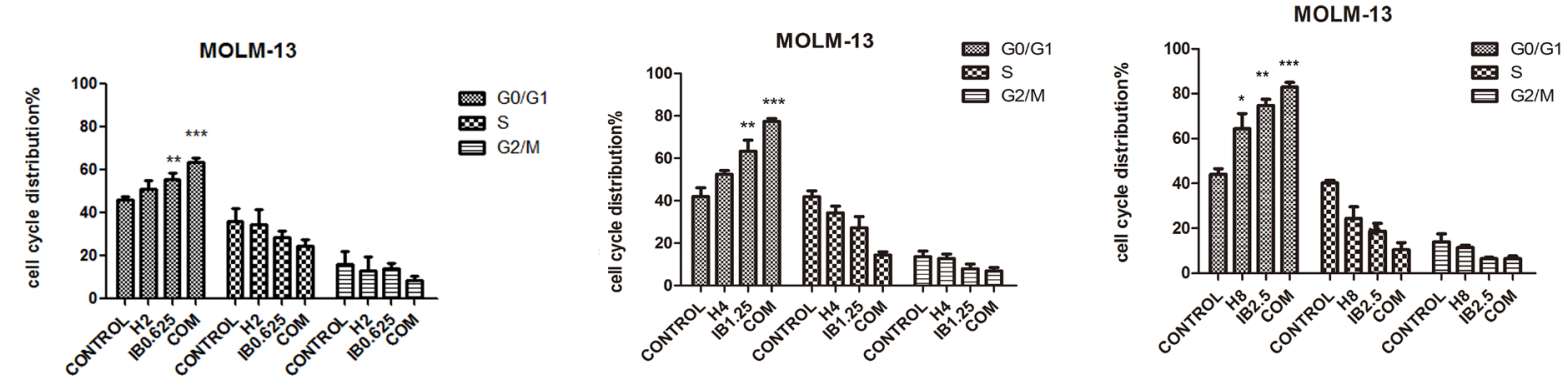

C
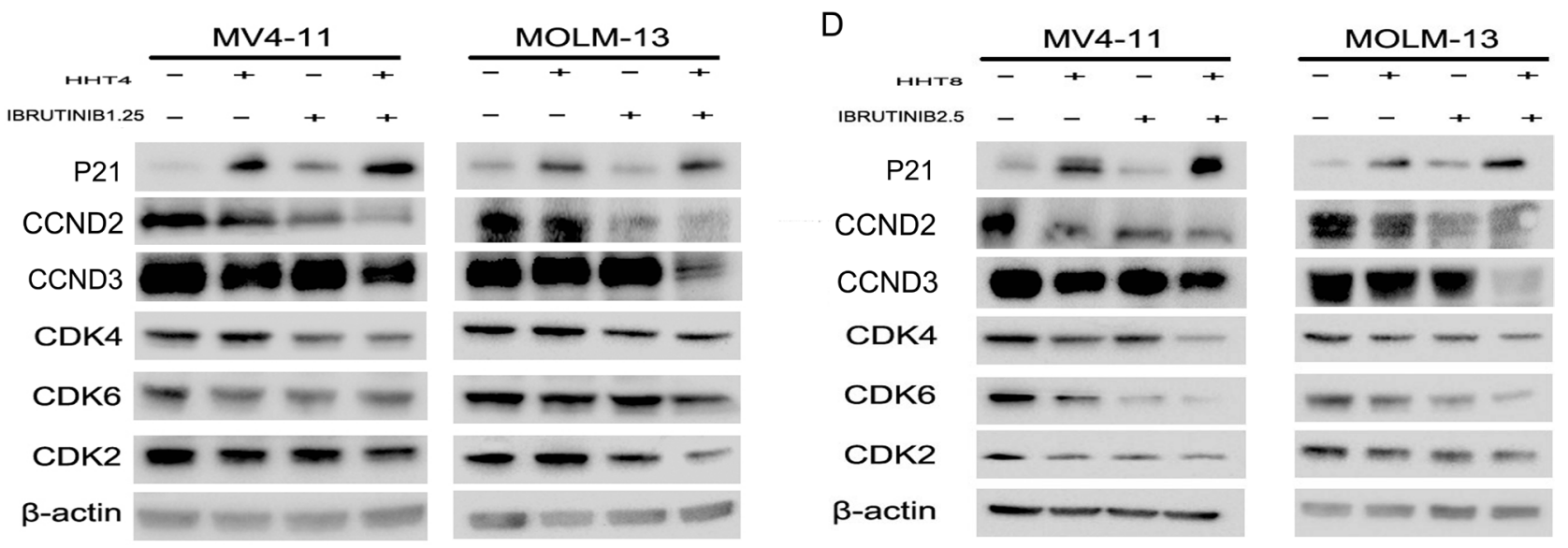

Figure 5: Effects of HHT, ibrutinib, HHT+ibrutinib on cell cycle distribution in AML cells. (A) MV4-11 and MOLM-13 cells were treated with $4 \mathrm{nM} \mathrm{HHT}$ and/or $1.25 \mu \mathrm{M}$ ibrutinib for $24 \mathrm{~h}$. (B) MV4-11 and MOLM-13 cells were treated with $8 \mathrm{nM}$ HHT or/ and $2.5 \mu \mathrm{M}$ ibrutinib for $24 \mathrm{~h}$. The cells were stained with propidium iodide and subjected to flowcytometry analysis to determine cell cycle distribution. (C and D) Soluble proteins P21, CCDN2, CCDN3, CDK4, CDK6, CDK2 and $\beta$-actin were analyzed by Western blotting analyses at the indicated concentrations for $24 \mathrm{~h}$.
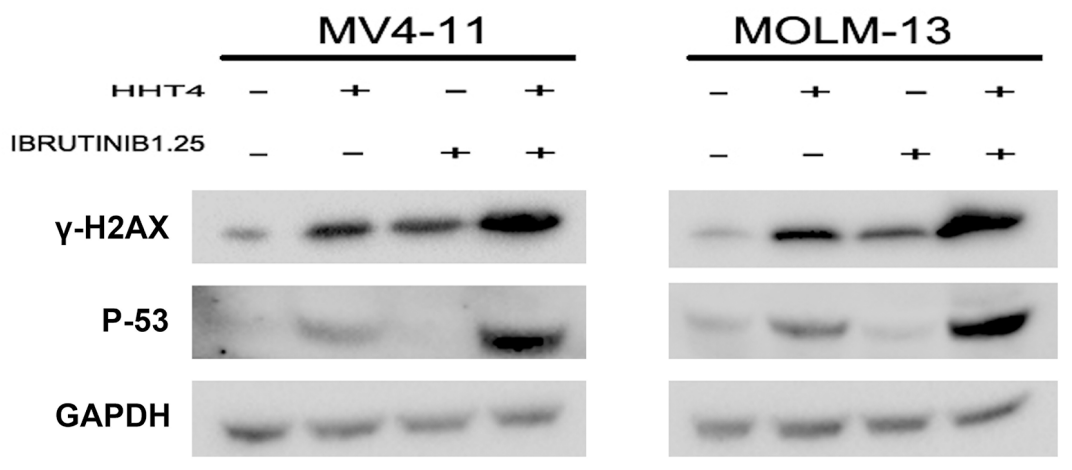

Figure 6: The synergistic effects increased $\gamma \mathrm{H} 2 \mathrm{AX}$ and p53. The protein levels of $\gamma \mathrm{H} 2 \mathrm{AX}$ and $\mathrm{p} 53$ were examined by western blot. 
AKT and STAT5 signaling pathways at high concentration but not ERK in FLT3-ITD mutant AML cells. In addition, we firstly found that HHT up-regulated the levels of P53 and P21WAF1/CIP1. Most importantly, HHT obviously decreased not only p-FLT3 but also total FLT3.

The pharmacological mechanisms by which ibrutinib inhibits FLT3-ITD mutant AML cells are more legible. A recent study by Pillinger et al demonstrated that BTK was activated in the downstream of the FLT3-ITD in AML and that ibrutinib induced survival and proliferation pathways including AKT, STAT5 and MAPK via targeting FLT3-ITD [25]. Our results were almost consistent. However, no obvious effect on MAPK pathway at $6 \mathrm{~h}$ point was observed in our study. For the mechanisms of synergistic effect, we found that HHT combined with ibrutinib induced simultaneous up-regulation of PARP, Caspases, $\gamma \mathrm{H} 2 \mathrm{AX}$, P53, P21 WAF1/CIP1 and down-regulation of CCND2, CCND3, CDK4, 6, 2, P-AKT, P-STAT5/Pim-2/C-Myc and $\mathrm{Bcl}-2$ family at the protein level in FLT3-ITD mutant AML cells. Supplementary Figure 2 summarized the pathway for combination mechanisms. Above all, for the combination of HHT and ibrutinib, it obviously decreased both total FLT3 and p-FLT3. Meanwhile, the combination group caused a more significant decrease in the expression of $\mathrm{p}-\mathrm{BTK}$. The combination of HHT and ibrutinib simultaneously inhibited first the activity of FLT3 and BTK and then STAT5 and C-Myc. These processes caused DNA damage, induced P53 overexpression, activated P21, and then triggered cell cycle arrest and apoptosis. This phenomenon was highlighted in FLT3-ITD+ cells. However, the combination group still can't inhibit P-ERK. Therefore, further studies are of great necessity to combine another antineoplastic agent to down regulate ERK pathway and explore a more effective chemotherapy regimen.

Therefore, we conclude that co-treatment with HHT and ibrutinib is a potentially new therapeutic regimen for FLT3-ITD mutant AML and further clinical studies are required.

\section{MATERIALS AND METHODS}

\section{Materials}

Anti-phosphorylated and total FLT3, BTK (223), AKT, STAT5 and ERK, CCDN2, CCND3, CDK2, CDK4, CDK6, P53, $\gamma \mathrm{H} 2 \mathrm{AX}, \mathrm{P} 21 \mathrm{WAF} 1 / \mathrm{CIP} 1, \mathrm{CASPASE}-3$, CASPASE-7, CASPASE-8, PARP, Bad, Bax, Bcl-2, BclXL, MCL-1, Pim-2, $\gamma$-H2AX, and $\beta$-actin antibodies were
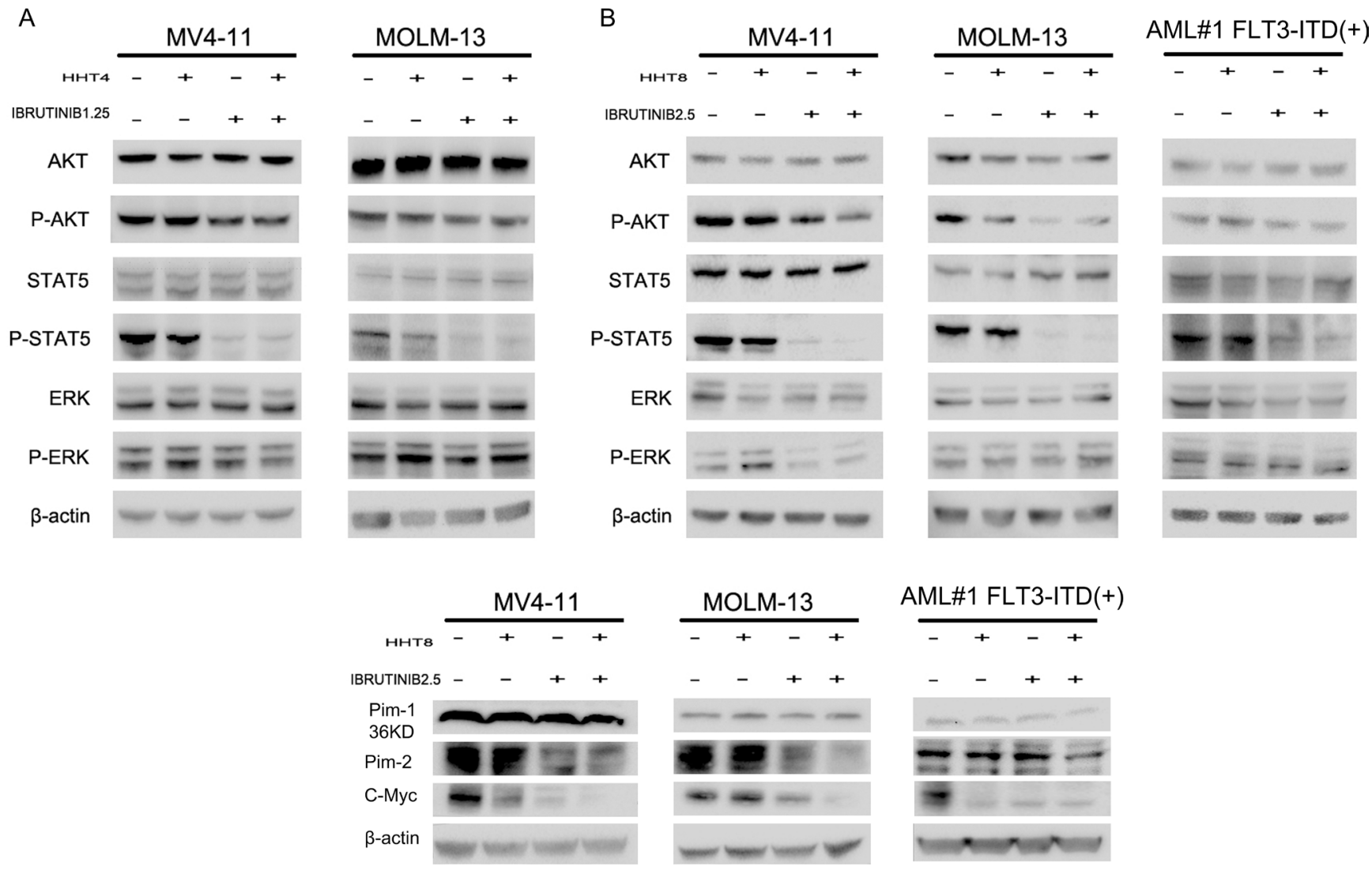

Figure 7: HHT combination ibrutinib inhibits STAT5, AKT signaling. (A and C) MV4-11 and MOLM-13 cells were treated with $4 \mathrm{nM} \mathrm{HHT}$ and/or 1.25 ibrutinib for $6 \mathrm{~h}$. (B and D) MV4-11, MOLM-13 and primary AML cells were treated with $8 \mathrm{nM}$ HHT or/and $2.5 \mu \mathrm{M}$ ibrutinib for $6 \mathrm{~h}$. Western blot analysis was conducted for p-AKT-S473, total AKT, p-STAT5, STAT5, p-ERK, ERK, Pim-1, Pim-2 and C-Myc protein levels. 


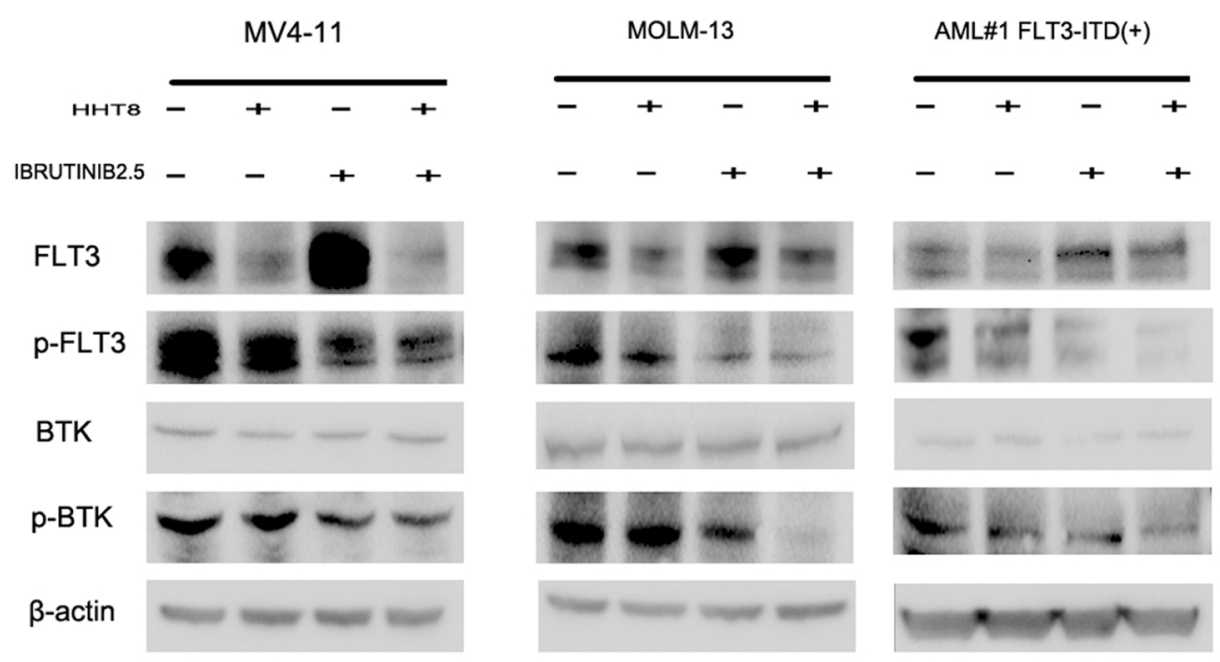

Figure 8: The level of main target proteins were analyzed when cells were exposed to drugs for 24 h. MV4-11, MOLM-13 and primary AML cells were treated with $8 \mathrm{nM}$ HHT and/or $2.5 \mu \mathrm{M}$ ibrutinib for $24 \mathrm{~h}$. Western blot analysis was conducted for FLT3, p-FLT3, BTK, and p-BTK223 protein levels.

A
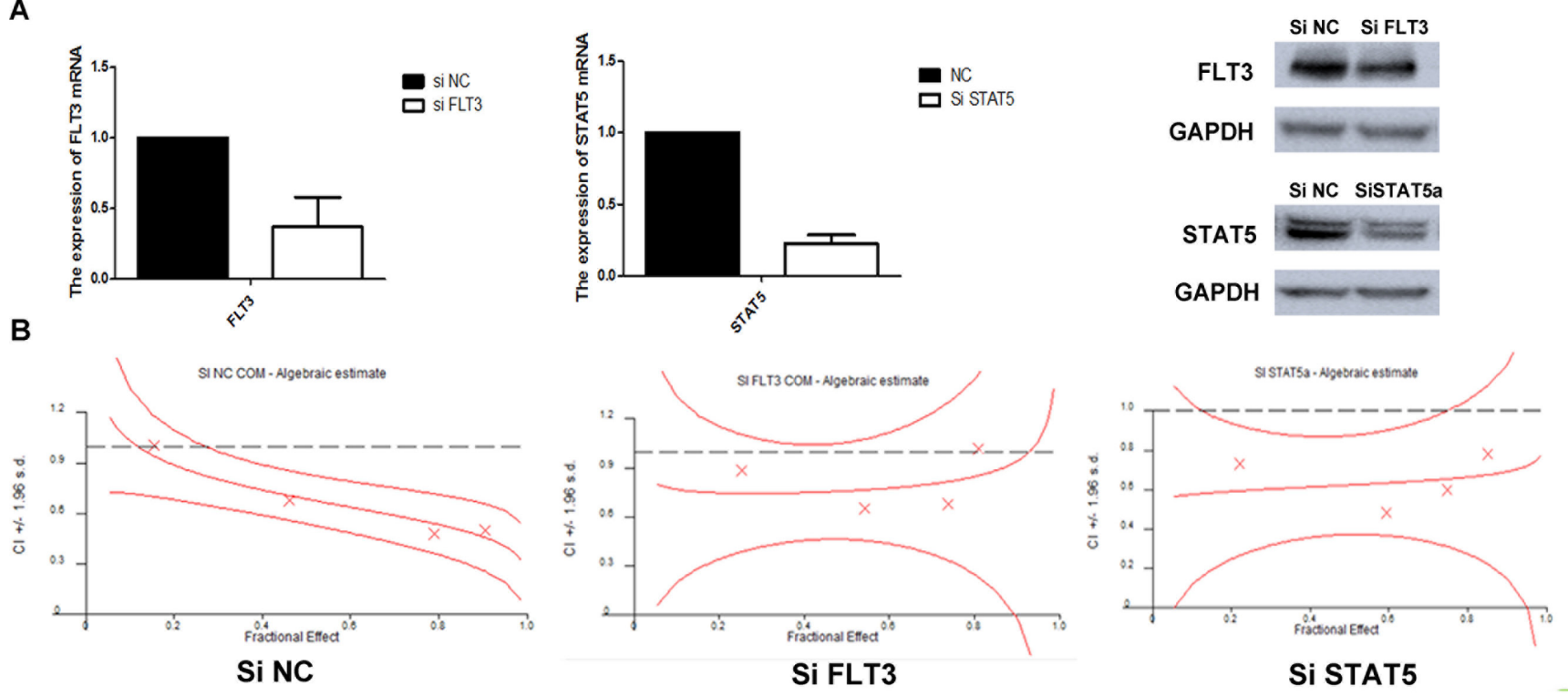

\begin{tabular}{cccc} 
& \multicolumn{3}{c}{ Combination Index Values } \\
\cline { 2 - 4 } & SiNC & Si FLT3 & Si STAT5 \\
\hline ED-50 & 0.686 & 0.760 & 0.624 \\
ED-75 & 0.562 & 0.821 & 0.655 \\
ED-90 & 0.461 & 0.943 & 0.692 \\
\hline
\end{tabular}

C

MV4-11

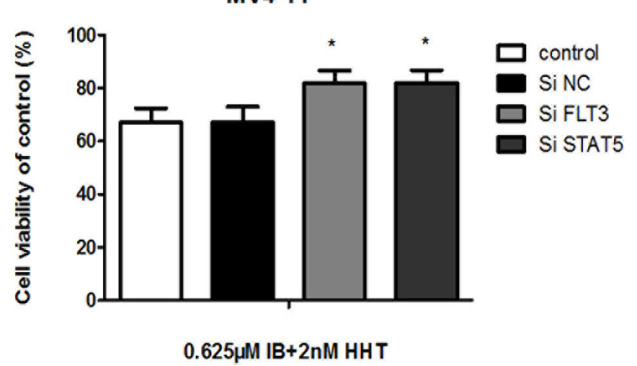

Figure 9: Ibrutinib's synergy with HHT is dependent of FLT3. MV4-11 cells were transduced with 3 different SiRNAs targeting FLT3, STAT5 or a non-targeting siRNA control. The reduction of FLT3 or STAT5 expression was confirmed by qPCR and western blotting. (A) On day 3 to 5 post-transduction, cells were treated with HHT at concentrations previously shown to synergize with ibrutinib for $24 \mathrm{~h}$. The CIs at the ED50, ED75 and ED90 were presented. (B) Cells were treated with $0.625 \mu \mathrm{M}$ ibrutinib and $2 \mathrm{nM}$ HHT for $48 \mathrm{~h}$. Cell growth and viability was determined by a MTT assay. (C) The data are presented as mean inhibition rates \pm SD from at least three independent experiments. 
purchased from Cell Signalling Technology (Beverly, MA, USA). Pim-1 was obtained from Abcam (Cambridge, MA). Ibrutinib was obtained from Selleck Chemicals (Houston, USA). HHT was purchased from Sigma-Aldrich (St. Louis, MO, USA).

\section{Methods}

\section{Cell lines and primary cells}

The FLT3-ITD+ AML cell lines MV4-11 and MOLM-13 were kindly endowed by Professor Ravi Bhatia (City of Hope National Medical Center, Duarte, CA). These two cell lines were cultured in IMDM medium (Gibco, Billings, MT, USA) supplemented with 10\% fetal bovine serum (Gibco) at $37^{\circ} \mathrm{C}$ in a humidified incubator containing 5\% CO2. Bone-marrow samples were obtained from AML patients after obtaining written informed consent. Peripheral blood mononuclear cells (PBMCs) were isolated by Ficoll-Hypaque (Sigma-Aldrich) density gradient centrifugation. The mutations in FLT3 internal tandem duplication (FLT-3ITD) were tested by the First Affiliated Hospital (Zhejiang University College of Medicine). The study was approved by the Ethics Committee of the First Affiliated Hospital, College of Medicine, Zhejiang University (Hangzhou, China).

\section{Growth inhibition assay}

Cells were seeded in 96-well plates at $1 \times 10^{5}$ (cellline cells) or $5 \times 10^{5}$ (primary AML cells). After treated with different drugs for $24 \mathrm{~h}, 20 \mathrm{ul}$ MTT solution $(5 \mathrm{mg} / \mathrm{mL})$ was added to each well and the cells were incubated for an additional $4 \mathrm{~h}$ at $37^{\circ} \mathrm{C}$. The cell medium was then removed and 200 ul DMSO was added to the 96-well plates to dissolve the MTT crystals. The plates were read at an absorbance of $570 \mathrm{~nm}$. Cell-lines experiments were repeated three times.

\section{Apoptosis assay}

Cells were treated with drugs for $24 \mathrm{~h}$ and $48 \mathrm{~h}$ and then harvested. After washed twice with phosphate buffered saline (PBS), cells were resuspended in binding buffer. Cells were then co-stained with 5 ul AnnexinV-Fluorescein Isothiocyanate (FITC) and 5 ul Propidium Iodide (PI) using an apoptosis detection kit (BD Pharmingen, San Diego, CA, USA). The apoptic cells were analyzed by FACScan flow cytometer (Becton Dickinson, San Diego, CA, USA).

\section{Cell cycle analysis}

Cells were treated with drugs for $24 \mathrm{~h}$. At the end of the treatment, the cells were washed with PBS and fixed with $75 \%$ ethanol at $4^{\circ} \mathrm{C}$. The next day, the cells were harvested and washed with PBS twice then resuspended in buffer with $50 \mu \mathrm{g} / \mathrm{ml}$ PI (propidium iodide) and $100 \mu \mathrm{g} / \mathrm{ml}$ RNase A for $30 \mathrm{~min}$. The DNA content was analysed by
FACScan flow cytometer (Becton Dickinson, San Diego, CA, USA).

\section{Western blot analysis}

Cells from various conditions were harvested and washed twice in PBS and lysed a RIPA buffer (Cell Signaling Technology, Beverly, MA, USA) on ice for $30 \mathrm{~min}$. Cells were then centrifuged at $12000 \mathrm{~g}$ for $15 \mathrm{~min}$ at $4{ }^{\circ} \mathrm{C}$ and the supernatant was collected. The protein concentration was determined using BCA reagent. Protein samples were separated via 10\% SDS-PAGE gel (Life Technology, USA) and transferred to a PVDF membrane (Millipore, Billerica, MA, USA). Next, the membranes were blocked in Tris-buffered solution (TBS) containing 5\% non-fat milk for $1 \mathrm{~h}$ and incubated with primary antibodies overnight at $4^{\circ} \mathrm{C}$. After washed with TBS-T buffer three times, membranes were incubated with secondary antibodies (CST, Beverly, MA, USA) for $1.5 \mathrm{~h}$. The target protein bands were visualized using an ECL kit (Thermo scientific, USA) and analysis by the image lab software (bio-rad, california, USA)

\section{Real-time reverse transcription-polymerase chain reaction (RT-PCR)}

Total RNA was extracted using TRIzol (Invitrogen, Carlsbad, CA, USA). About 500 ng of total RNA was used for reverse transcription reaction. Quantitative PCR was performed in triplicate using SYBR-Green PCR Master Mix kit (Takara, Japan) on an IQ5 real time PCR instrument (Bio-Rad, USA). The primers sequences were as follows: FLT3 5'-CTGAATTGCCAGCCACATTTTG-3' (forward) and 5'-GGAACGCTCTCAGATATGCAG-3' (reverse); STAT5 5'-GCAGAGTCCGTGACAGAGG-3' (forward) and 5'-CCACAGGTAGGGACAGAGTCT-3' (reverse); GAPDH 5'-TCAACGACCACTTTGTCAAGCTCA-3' (forward) and 5'- GCTGGTGGTCCAGGGGTCTTACT-3' (reverse).

\section{RNA interference}

FLT3 and STAT5 siRNA were purchased from Novars (Shenzhen, china). Transfection was performed using LipofectamineTM RNAiMAX (Invitrogen) according to the manufacturer's instructions. MV4-11 cells were seeded at $5 \times 10^{5} /$ well in 6-well plates. A total of $200 \mathrm{nM}$ of each siRNA and 10 ul Lipofectamine were mixed in $250 \mathrm{ul}$ OptiMEM (Invitrogen). After incubation at room temperature for $10 \mathrm{~min}$, the siRNA-lipid complex was added to cells, incubated at $37^{\circ} \mathrm{C}$ for $72 \mathrm{~h}$ and then cells were collected for RT-PCR, Western blotting and MTT assay.

\section{Statistical analysis}

The combination index (CI) was calculated using CalcuSyn software (Biosoft, Cambridge, UK). Student's 
$t$-test was used to assess statistical significance. Results with $P<0.05$ were considered to indicate a statistically significant difference $(*)$. Results represented the mean \pm SD of 3 independent experiments.

\section{ACKNOWLEDGMENTS AND FUNDING}

We would like to thank Professor Ravi Bhatia for providing us with the MV4-11 and MOLM-13 cell lines. This work was supported by the National Natural Science Foundation of China (Grant number: 81370643-H0812) and Zhejiang Provincial Key Innovation Team (Grant number: 2011R50015).

\section{CONFLICTS OF INTEREST}

The authors declare no competing financial interests

\section{REFERENCES}

1. Wiernik PH, Banks PL, Case DC Jr., Arlin ZA, Periman PO, Todd MB, Ritch PS, Enck RE, Weitberg AB. Cytarabine plus idarubicin or daunorubicin as induction and consolidation therapy for previously untreated adult patients with acute myeloid leukemia. Blood. 1992; 79:313-319.

2. Phillips GL, Reece DE, Shepherd JD, Barnett MJ, Brown RA, Frei-Lahr DA, Klingemann HG, Bolwell BJ, Spinelli JJ, Herzig RH, et al. High-dose cytarabine and daunorubicin induction and postremission chemotherapy for the treatment of acute myelogenous leukemia in adults. Blood. 1991; 77:1429-1435.

3. Kiyoi H, Yanada M, Ozekia K. Clinical significance of FLT3 in leukemia. International journal of hematology. 2005; 82:85-92.

4. Xu YY, Gao L, Ding Y, Sun JZ, Wang N, Wang LL, Yu L. [Detection and clinical significance of FLT3-ITD gene mutation in patients with acute myeloid leukemia]. Zhongguo shi yan xue ye xue za zhi/Zhongguo bing li sheng li xue hui $=$ Journal of experimental hematology / Chinese Association of Pathophysiology. 2012; 20:1312-1315.

5. Thiede C, Steudel C, Mohr B, Schaich M, Schakel U, Platzbecker U, Wermke M, Bornhauser M, Ritter M, Neubauer A, Ehninger G, Illmer T. Analysis of FLT3activating mutations in 979 patients with acute myelogenous leukemia: association with FAB subtypes and identification of subgroups with poor prognosis. Blood. 2002; 99:4326-4335.

6. Ravandi F, Kantarjian H, Faderl S, Garcia-Manero G, O'Brien S, Koller C, Pierce S, Brandt M, Kennedy D, Cortes J, Beran M. Outcome of patients with FLT3-mutated acute myeloid leukemia in first relapse. Leukemia research. 2010; 34:752-756.

7. Fresno M, Jimenez A, Vazquez D. Inhibition of translation in eukaryotic systems by harringtonine. European journal of biochemistry. 1977; 72:323-330.
8. Tang R, Faussat AM, Majdak P, Marzac C, Dubrulle S, Marjanovic Z, Legrand O, Marie JP. Semisynthetic homoharringtonine induces apoptosis via inhibition of protein synthesis and triggers rapid myeloid cell leukemia-1 down-regulation in myeloid leukemia cells. Molecular cancer therapeutics. 2006; 5:723-731.

9. Gu Y, Zhou H, Gan Y, Zhang J, Chen J, Gan X, Li H, Zheng W, Meng Z, Ma X, Wang X, Xu X, Xu G, et al. Small-molecule induction of phospho-eIF4E sumoylation and degradation via targeting its phosphorylated serine 209 residue. Oncotarget. 2015; 6:15111-15121. doi: 10.18632/ oncotarget.3615.

10. Jin J, Wang JX, Chen FF, Wu DP, Hu J, Zhou JF, Hu JD, Wang JM, Li JY, Huang XJ, Ma J, Ji CY, Xu XP, et al. Homoharringtonine-based induction regimens for patients with de-novo acute myeloid leukaemia: a multicentre, openlabel, randomised, controlled phase 3 trial. The Lancet Oncology. 2013; 14:599-608.

11. Wang L, You LS, Ni WM, Ma QL, Tong Y, Mao LP, Qian JJ, Jin J. beta-Catenin and AKT are promising targets for combination therapy in acute myeloid leukemia. Leukemia research. 2013; 37:1329-1340.

12. Yu W, Mao L, Qian J, Qian W, Meng H, Mai W, Tong H, Tong Y, Jin J. Homoharringtonine in combination with cytarabine and aclarubicin in the treatment of refractory/ relapsed acute myeloid leukemia: a single-center experience. Annals of hematology. 2013; 92:1091-1100.

13. Jie $H$, Donghua $H$, Xingkui $X$, Liang $G$, Wenjun $W$, Xiaoyan H, Zhen C. Homoharringtonine-induced apoptosis of MDS cell line MUTZ-1 cells is mediated by the endoplasmic reticulum stress pathway. Leukemia \& lymphoma. 2007; 48:964-977.

14. Feldman EJ, Seiter KP, Ahmed T, Baskind P, Arlin ZA. Homoharringtonine in patients with myelodysplastic syndrome (MDS) and MDS evolving to acute myeloid leukemia. Leukemia. 1996; 10:40-42.

15. Wu L, Li X, Su J, He Q, Zhang X, Chang C, Pu Q. Efficacy and safety of $\mathrm{CHG}$ regimen (low-dose cytarabine, homoharringtonine with G-CSF priming) as induction chemotherapy for elderly patients with high-risk MDS or AML transformed from MDS. Journal of cancer research and clinical oncology. 2011; 137:1563-1569.

16. Zhou X, Xu N, Li R, Xiao Y, Gao G, Lu Q, Ding L, Li L, Li Y, Du Q, Liu X. A comparative proteomic study of Homoharringtonine-induced apoptosis in leukemia K562 cells. Leukemia \& lymphoma. 2015; 56:2162-2169.

17. Alvandi F, Kwitkowski VE, Ko CW, Rothmann MD, Ricci S, Saber H, Ghosh D, Brown J, Pfeiler E, Chikhale E, Grillo J, Bullock J, Kane R, et al. U.S. Food and Drug Administration approval summary: omacetaxine mepesuccinate as treatment for chronic myeloid leukemia. The oncologist. 2014; 19:94-99.

18. Cortes J, Lipton JH, Rea D, Digumarti R, Chuah C, Nanda N, Benichou AC, Craig AR, Michallet M, 
Nicolini FE, Kantarjian H and Omacetaxine 202 Study G. Phase 2 study of subcutaneous omacetaxine mepesuccinate after TKI failure in patients with chronic-phase CML with T315I mutation. Blood. 2012; 120:2573-2580.

19. Khoury HJ, Cortes J, Baccarani M, Wetzler M, Masszi T, Digumarti R, Craig A, Benichou AC, Akard L. Omacetaxine mepesuccinate in patients with advanced chronic myeloid leukemia with resistance or intolerance to tyrosine kinase inhibitors. Leukemia \& lymphoma. 2015; 56:120-127.

20. Xu G, Mao L, Liu H, Yang M, Jin J, Qian W. Sorafenib in combination with low-dose-homoharringtonine as a salvage therapy in primary refractory FLT3-ITD-positive AML: a case report and review of literature. International journal of clinical and experimental medicine. 2015; 8:19891-19894.

21. Rushworth SA, Murray MY, Zaitseva L, Bowles KM, MacEwan DJ. Identification of Bruton's tyrosine kinase as a therapeutic target in acute myeloid leukemia. Blood. 2014; 123:1229-1238.

22. Zaitseva L, Murray MY, Shafat MS, Lawes MJ, MacEwan DJ, Bowles KM, Rushworth SA. Ibrutinib inhibits SDF1/CXCR4 mediated migration in AML. Oncotarget. 2014; 5:9930-9938. doi: 10.18632/ oncotarget.2479.

23. Oellerich T, Mohr S, Corso J, Beck J, Dobele C, Braun H, Cremer A, Munch S, Wicht J, Oellerich MF, Bug G, Bohnenberger H, Perske C, et al. FLT3-ITD and TLR9 use Bruton tyrosine kinase to activate distinct transcriptional programs mediating AML cell survival and proliferation. Blood. 2015; 125:1936-1947.

24. Rotin LE, Gronda M, MacLean N, Hurren R, Wang X, Lin FH, Wrana J, Datti A, Barber DL, Minden MD, Slassi M, Schimmer AD. Ibrutinib synergizes with poly (ADP-ribose) glycohydrolase inhibitors to induce cell death in AML cells via a BTK-independent mechanism. Oncotarget. 2016; 7:2765-79. doi: 10.18632/oncotarget.6409.

25. Pillinger G, Abdul-Aziz A, Zaitseva L, Lawes M, MacEwan DJ, Bowles KM, Rushworth SA. Targeting BTK for the treatment of FLT3-ITD mutated acute myeloid leukemia. Scientific reports. 2015; 5:12949.

26. Wu H, Hu C, Wang A, Weisberg EL, Wang W, Chen C, Zhao Z, Yu K, Liu J, Wu J, Nonami A, Wang L, Wang B, et al. Ibrutinib selectively targets FLT3-ITD in mutant FLT3-positive AML. Leukemia. 2015.

27. Wu H, Hu C, Wang A, Weisberg EL, Wang W, Chen C, Zhao Z, Yu K, Liu J, Wu J, Nonami A, Wang L, Wang B, et al. Ibrutinib selectively targets FLT3-ITD in mutant FLT3positive AML. Leukemia. 2016; 30:754-757.

28. Shelburne CP, McCoy ME, Piekorz R, Sexl VV, Gillespie SR, Bailey DP, Gharse A, Mirmonsef P, Mann MN, Kashyap M, Wright HV, Chong HJ, Bouton LA, et al. Stat5: an essential regulator of mast cell biology. Molecular immunology. 2002; 38:1187-1191.

29. Kieslinger M, Woldman I, Moriggl R, Hofmann J, Marine JC, Ihle JN, Beug H, Decker T. Antiapoptotic activity of Stat5 required during terminal stages of myeloid differentiation. Genes \& development. 2000; 14:232-244.

30. Dumon S, Santos SC, Debierre-Grockiego F, GouilleuxGruart V, Cocault L, Boucheron C, Mollat P, Gisselbrecht S, Gouilleux F. IL-3 dependent regulation of Bcl-xL gene expression by STAT5 in a bone marrow derived cell line. Oncogene. 1999; 18:4191-4199.

31. Giri S, Hamdeh S, Bhatt VR, Schwarz JK. Sorafenib in Relapsed AML With FMS-Like Receptor Tyrosine Kinase-3 Internal Tandem Duplication Mutation. Journal of the National Comprehensive Cancer Network. 2015; 13:508-514.

32. Man CH, Fung TK, Ho C, Han HH, Chow HC, Ma AC, Choi WW, Lok S, Cheung AM, Eaves C, Kwong YL, Leung AY. Sorafenib treatment of FLT3-ITD $(+)$ acute myeloid leukemia: favorable initial outcome and mechanisms of subsequent nonresponsiveness associated with the emergence of a D835 mutation. Blood. 2012; 119:5133-5143.

33. Stone RM, Fischer T, Paquette R, Schiller G, Schiffer CA, Ehninger G, Cortes J, Kantarjian HM, DeAngelo DJ, Huntsman-Labed A, Dutreix C, del Corral A, Giles F. Phase IB study of the FLT3 kinase inhibitor midostaurin with chemotherapy in younger newly diagnosed adult patients with acute myeloid leukemia. Leukemia. 2012; 26:2061-2068.

34. Knapper S, Burnett AK, Littlewood T, Kell WJ, Agrawal S, Chopra R, Clark R, Levis MJ, Small D. A phase 2 trial of the FLT3 inhibitor lestaurtinib (CEP701) as first-line treatment for older patients with acute myeloid leukemia not considered fit for intensive chemotherapy. Blood. 2006; 108:3262-3270.

35. Cortes JE, Kantarjian H, Foran JM, Ghirdaladze D, Zodelava M, Borthakur G, Gammon G, Trone D, Armstrong RC, James J, Levis M. Phase I study of quizartinib administered daily to patients with relapsed or refractory acute myeloid leukemia irrespective of FMS-like tyrosine kinase 3-internal tandem duplication status. Journal of clinical oncology. 2013; 31:3681-3687.

36. Levis M. Quizartinib for the treatment of FLT3/ITD acute myeloid leukemia. Future oncology. 2014; 10:1571-1579.

37. Tong H, Ren Y, Zhang F, Jin J. Homoharringtonine affects the JAK2-STAT5 signal pathway through alteration of protein tyrosine kinase phosphorylation in acute myeloid leukemia cells. European journal of haematology. 2008; 81:259-266. 